\title{
Phenotypic Correction of Fanconi Anemia in Human Hematopoietic Cells with a Recombinant Adeno-associated Virus Vector
}

\author{
Christopher E. Walsh, * Arthur W. Nienhuis, ${ }^{\ddagger}$ Richard Jude Samulski, ${ }^{\S}$ Michael G. Brown," Jeffery L. Miller, * \\ Neal S. Young, * and Johnson M. Liu* \\ *Hematology Branch, National Heart, Lung, and Blood Institute, National Institutes of Health, Bethesda, Maryland 20892; ${ }^{\ddagger}$ St. Jude \\ Children's Research Hospital, Memphis, Tennessee 38112; ${ }^{8}$ Department of Pharmacology, University of North Carolina, Chapel Hill, \\ North Carolina 27599; and "Oregon Health Sciences University, Portland, Oregon 97201
}

\begin{abstract}
Fanconi anemia (FA) is a recessive inherited disease characterized by defective DNA repair. FA cells are hypersensitive to DNA cross-linking agents that cause chromosomal instability and cell death. FA is manifested clinically by progressive pancytopenia, variable physical anomalies, and predisposition to malignancy. Four complementation groups have been identified, termed $A, B, C$, and $D$. The gene for the FA complementation group C, FACC, has been cloned. Expression of the FACC cDNA corrects the phenotypic defect of FA ( C ) cells, resulting in normalized cell growth in the presence of DNA cross-linking agents such as mitomycin $\mathrm{C}$ (MMC). Gene transfer of the FACC gene should provide a survival advantage to transduced hematopoietic cells, suggesting that FA might be an ideal candidate for gene therapy. We demonstrated efficient transduction, expression, and phenotypic correction in lymphoblastoid cell lines derived from $F A(C)$ patients using a recombinant adeno-associated virus ( $\mathrm{FAAV}$ ) vector containing the FACC gene. Molecular characterization of the transduced FACC gene showed an intact unrearranged proviral genome with expression sufficient to normalize cell growth, cell cycle kinetics and chromosomal breakage in the presence of MMC. These observations were extended by testing rAAV transduction in hematopoietic progenitor cells. Peripheral blood CD34+ cells isolated from a FA $(C)$ patient and transduced with rAAV/FACC virus yielded 5-10-fold more progenitor colonies than mock-infected cells, consistent with genetic "rescue" of corrected cells. This is the first demonstration of rAAV gene correction in primary human hematopoietic progenitor cells and has important implications for gene therapy of hematopoietic disorders, specifically FA. ( J. Clin. Invest. 1994. 94:1440-1448.) Key words: gene therapy • transduction - DNA repair - hematopoiesis
\end{abstract}

\section{Introduction}

Fanconi anemia (FA) ${ }^{1}$ is an autosomal recessive disorder characterized by pancytopenia, physical anomalies, and susceptibil-

Address correspondence to Christopher E. Walsh, Hematology Branch, NHLBI, National Institutes of Health, Bethesda, MD 20892. 1994.

Received for publication 11 March 1994 and in revised form 2 June

1. Abbreviations used in this paper: AAV, adeno-associated virus; rAAV, recombinant adeno-associated virus; DEB, diepoxybutane; FA, Fanconi anemia; FACC Fanconi anemia C complementing; MMC, mitomycin $\mathrm{C}$.

The Journal of Clinical Investigation, Inc.

Volume 94, October 1994, 1440-1448 ity to malignancy (1). Most patients are diagnosed in the first decade of life and die as young adults, usually from complications of severe bone marrow failure or, more rarely, from the development of acute leukemia or solid tumors. Therapy is currently limited to allogeneic bone marrow transplantation from a histocompatible sibling, but most patients do not have an appropriate marrow donor (2).

Although the biochemical defect in FA has not been delineated, several lines of evidence implicate a defect of DNA repair. Cells derived from FA patients exhibit a marked increase in the number of spontaneous chromosomal aberrations compared to cells from normal individuals $(3,4)$. Chromosomal breakage is enhanced when FA cells are incubated in the presence of the DNA cross-linking agents mitomycin C (MMC) and diepoxybutane (DEB) $(5,6)$. Hypersensitivity to these agents is also reflected by delayed transit through the $\mathrm{G} 2$ phase of the cell cycle (7) and by accelerated cell death (8). Chromosomal breakage, abnormal cellular sensitivity to DNA damage, and aberrant cell cycle kinetics are features which link FA nosologically with other DNA repair disorders such as xeroderma pigmentosum, ataxia telangiectasia, and Bloom's syndrome.

Somatic cell fusion methods have established that at least four different genes can cause FA (9). A novel gene termed FACC (Fanconi anemia C complementing) has been identified by functional complementation cloning (10). This gene, which maps to chromosome $9 \mathrm{q}$, shares no homology to any known gene. The FACC protein has a predicted molecular weight of $63 \mathrm{kD}$. FACC mutations have been identified in $\sim 15 \%$ of all FA patients $(11,12)$. In tissue culture, transfected FACC cDNA corrects the phenotypic defect, resulting in normalized cell growth in the presence of MMC or DEB (10). Because FA cells proliferate poorly, transfer of the FACC gene should provide a survival advantage to the gene-corrected FA cells, making this disease an ideal candidate for human gene therapy.

Correction of the Fanconi anemia phenotype provides a unique paradigm to test the novel recombinant adeno-associated virus (rAAV) gene transfer system. The adeno-associated virus (AAV) is a single-stranded DNA parvovirus which requires a helper virus, such as adenovirus, for replication and viral production in permissive cells (for reviews see references 1315). In the absence of helper virus, AAV can persist as an integrated provirus in susceptible cells. Unlike other viruses, wild-type AAV is unique in that it integrates preferentially at a specific locus on chromosome $19 q(16-18)$. Virtually any mammalian cell line can be productively or latently infected. Despite its broad host range, no disease has been associated with AAV in human or animal populations suggesting that AAV would be an attractive alternative to other established viral vectors.

We previously demonstrated the utility of rAAV as a gene transfer vector for the human gamma globin gene into the eryth- 
roleukemia cell line, K562 (19). Further studies have used this vector to characterize cis-acting elements required for globin expression (20). Suppression of HIV-1 gene expression and replication has been documented in lymphoid cell lines using a rAAV vector carrying HIV-1 antisense sequences (21). In addition, rAAV transduction of primary hematopoietic progenitors has been demonstrated using marker genes $(22,22 a)$. The self-selecting growth advantage that the FACC gene confers allows for a functional assay to test gene transduction in FA(C) hematopoietic progenitor cells. We report the first demonstration of rAAV vector transduction of human FA(C) hematopoietic cells and correction of the FACC phenotype.

\section{Methods}

Viruses and cells. Human adenovirus type 5 was obtained from the American Type Culture Collection (Rockville, MD). Epstein-Barr virus (EBV) transformed lymphoblast cell lines were generous gifts from Dr. Christopher Mathew (UMDS Guy's Hospital, London, UK) (BD0215) and Dr. Manuel Buchwald (Hospital for Sick Children, Toronto, Canada) (HSC536). All lymphoblasts were grown as previously described (10). Detroit 6 (D6) and 293 cells were maintained as previously described (19).

Plasmids and DNA. Plasmids pAAV/Ad, psub 201, and pUC008/ $\mathrm{Neo}^{\mathrm{R}}$ have been previously described $(19,23)$. The plasmid pFAC3 was kindly provided by Dr. Manuel Buchwald. This plasmid contains the FACC cDNA within a pREP4 backbone. pREP4 (Invitrogen, San Diego, CA) contains an expression cassette containing the Rous sarcoma virus (RSV) 3' LTR and Simian Virus (SV) 40 polyadenylation sequences.

Construction of $r A A V$ plasmids. The FACC cDNA was excised from the plasmid pFAC3 after digestion with SalI. This fragment was then subcloned into the SalI site of pUC19 (New England Biolabs, Beverly, MA). To remove the FACC 3 ' untranslated region, the pUC19 intermediate was digested with restriction enzymes $\mathrm{XbaI}$ (located at the stop codon of the FACC coding region) and NheI. These fragment ends were religated within the pREP4 polylinker, with the trimmed FACC lying between the RSV promoter and the SV40 polyadenylation site. The trimmed version of the FACC cDNA within the expression cassette derived from pREP4 was then subcloned into the SalI site of pUC008/ $\mathrm{Neo}^{\mathrm{R}}$. The RSV-driven FACC cDNA and the TK-driven neomycin phosphotransferase gene were then excised from $\mathrm{pUC008} / \mathrm{Neo}^{\mathrm{R}}$ with NheI and inserted into the XbaI site of psub201 to create pAAV/FACC/ $\mathrm{Neo}^{\mathrm{R}}$.

Generation of $r A A V$. Recombinant AAV were generated as previously described (19). Dishes $\left(10 \mathrm{~cm}^{2}\right)$ containing $60-80 \%$ confluent 293 cells were infected with adenovirus type 5. rAAV virions were generated by subsequent calcium phosphate cotransfection of $10 \mu \mathrm{g}$ of plasmid $\mathrm{pAAV} / \mathrm{FACC} / \mathrm{Neo}^{\mathrm{R}}$ and $10 \mu \mathrm{g}$ of helper plasmid (pAAV/ Ad). Cells were harvested $40 \mathrm{~h}$ posttransfection, frozen, and thawed four times, heat-treated $\left(56^{\circ} \mathrm{C}, 1 \mathrm{~h}\right)$ to inactivate adenovirus, and centrifuged to remove cellular debris.

Cell lysates were titered on D6 cells in the presence of $0.5 \mathrm{mg} / \mathrm{ml}$ Geneticin (GIBCO BRL, Grand Island, NY). Drug resistant colonies were isolated at 10-14 d. The rAAV titer was calculated from the number of resistant colonies and averaged $10^{4}-10^{5} \mathrm{NeO}^{\mathrm{R}}$ infectious particles per milliliter.

$r A A V$ Infection of $E B V$-transformed lymphoblasts. Lymphoblasts (1 $\left.\times 10^{5}\right)$ were infected with cell lysate $\left(3 \times 10^{4} \mathrm{Neo}^{\mathrm{R}}\right.$ infectious particles). Cells were harvested after $2 \mathrm{~d}$ and grown in $15 \%$ fetal calf serum/ RPMI with glutamine and antibiotics. Cells were passaged for $10 \mathrm{~d}$ and then resuspended at $2 \times 10^{5}$ cells per $\mathrm{ml}$ in the presence of active $\mathrm{G} 418$ $(0.2-0.6 \mathrm{mg} / \mathrm{ml})$. Noninfected lymphoblasts yielded no viable cells following drug selection. Drug-resistant cells were maintained in media containing G418 for 3-4 wk after infection.

Lymphoblast mitomycin $C(M M C)$ sensitivity. Cellular sensitivity to mitomycin C (Calbiochem-Behring Corp., San Diego, CA) was as- sayed by plating cells at a density of $2 \times 10^{5}$ per $\mathrm{ml}$ in 24 -well plates. Increasing concentrations of MMC were added, and after a 5-d incubation, cellular viability was assayed via Trypan blue exclusion. Each sample was performed in quadruplicate.

Cytogenetic analysis of transduced lymphoblasts. Lymphoblast cultures were analyzed for cytogenetic breakage and radial formation by exposure to MMC ( $40 \mathrm{ng} / \mathrm{ml}$ final) for $2 \mathrm{~d}$ in the dark. Cultures were harvested after a 1-h exposure to $0.25 \mu \mathrm{g} / \mathrm{ml}$ colcemid. After a $10 \mathrm{~min}$ treatment with $0.075 \mathrm{M} \mathrm{KCl}$, the cells were fixed with a $3: 1$ mixture of methanol: acetic acid. Slides were prepared using wet slides, air dried, and stained with Wright's stain. 50 metaphase figures from each culture were scored for obvious breaks, gaps larger than a chromatid width, and for radial formations.

Cell cycle analysis of transduced lymphoblasts. Lymphoblasts were plated at $2 \times 10^{5} / \mathrm{ml}$ and grown overnight. Either phosphate-buffered saline (PBS) or MMC (100 nM final concentration) was added and cells incubated for $24 \mathrm{~h}$. A total of $1 \times 10^{6}$ cells were resuspended in $1.0 \mathrm{ml}$ PBS with $2.0 \mathrm{ml}$ cold $70 \%$ ethanol and incubated on ice for 30 min. Cells were centrifuged and cell pellet incubated with propidium iodide $(20 \mu \mathrm{g} / \mathrm{ml}) / \mathrm{RNase} \mathrm{A}(0.04 \mathrm{mg} / \mathrm{ml})$ solution for $20 \mathrm{~min}$ at room temperature before analysis on an Epics Elite (Coulter Electronics Inc., Hialeah, FL) flow cytometer. Data was analyzed using the Multicycle software program based on the polynomial S-phase algorithm (Phoenix Flow Systems, San Diego, CA).

Southern blot analysis of genomic DNA. Genomic DNA digestion and Southern transfer was performed using ammonium acetate buffer (24) and Hybond N+ (Amersham Corp., Arlington Heights, IL) nylon filters. Blots were probed with a PstI (197 bp) $\mathrm{P}^{32}$-labeled fragment of the neomycin phosphotransferase gene, Neo ${ }^{R}$ (Stratagene, La Jolla, CA). Filters were washed to a final stringency of $2 \times \mathrm{SSC}$ at $65^{\circ} \mathrm{C}$ for $1 \mathrm{~h}$.

Analysis of lymphoblast FACC expression. RNA was extracted from transduced lymphoblasts as described (19). $1.0 \mu \mathrm{g}$ of RNA was reverse transcribed using the RNA PCR reagent kit (Perkin-Elmer Corp., Norwalk, CT). The cDNA sample was amplified using standard conditions including $\mathrm{P}^{32} \mathrm{dCTP}$. Primers specific for the endogenous FACC gene were: 5' CAC AGA CTA TGG TCC AGG TGA AGG 3' and 5' ACC AGG AGT ACC GAA GCT CAC TTG 3'. Primers specific for the transduced FACC gene were: 5' AAT TAC TGA TGT CGG CAG CCG AAC $3^{\prime}$ and 5' TTA TCA TGT CTG GAT CCG GCC TTG $3^{\prime}$. The amplification conditions used were: $95^{\circ} \mathrm{C}$ for $2 \mathrm{~min}$ followed by 30 cycles at $95^{\circ} \mathrm{C}$ for $30 \mathrm{~s}, 55^{\circ} \mathrm{C}$ for $30 \mathrm{~s}, 72^{\circ} \mathrm{C}$ for $1 \mathrm{~min}$, and then a $72^{\circ} \mathrm{C}$ extension for $8 \mathrm{~min}$. PCR products were separated on a $5 \%$ polyacrylamide gel, dried, and autoradiographed.

Metabolic labeling and immunoprecipitation. $\left[{ }^{35} \mathrm{~S}\right]$ Methionine (100 $\mu \mathrm{Ci}, 1,000 \mathrm{Ci} / \mathrm{mmol}$ ) (Amersham Corp.) labeling of lymphoblasts (1 $\times 10^{7}$ cells) was performed over $3 \mathrm{~h}$ and cells extracted in phosphate buffered saline, $\mathrm{pH} 7.5$, containing $1 \%$ (vol/vol) Triton-X-100, aprotinin $(1 \mu \mathrm{g} / \mathrm{ml}$, ICN Biomedicals, Inc., Aurora, $\mathrm{OH})$, leupeptin ( $1 \mu \mathrm{g} /$ $\mathrm{ml}$, ICN Biomedicals, Inc.), and AEBSF (10 $\mu \mathrm{g} / \mathrm{ml}$, ICN Biomedicals, Inc.). The extract was mixed with rabbit antiserum (1:200 dilution) raised against a glutathione S-transferase (GST)-FACC fusion protein (kindly provided by Dr. A. D'Andrea, Dana Farber Cancer Center). Immune complexes bound to protein A sepharose CL-4B (Pharmacia, Piscataway, NJ) were washed twice with $1 \%$ Triton X-100 and $0.1 \%$ SDS, and electrophoresed on a $10 \%$ SDS/polyacrylamide gel.

Isolation of CD34+ hematopoietic cells. Apheresis was performed after obtaining written informed consent from patients enrolled on a protocol approved by the National Heart, Lung, and Blood Institute Institutional Review Board. Peripheral blood (PB) cells were collected on a Fenwall CS3000 Blood Cell Separator. Mononuclear cells were obtained following Ficoll density gradient centrifugation and immunoselected on a Ceprate LC cell separation system (Cell Pro, Inc., Bothell, WA). Cells were incubated with a mouse IgM anti-human CD34, washed, and then incubated with a biotinylated goat anti-mouse IgM antibody. Cells were filtered through an avidin column and adsorbed cells eluted.

Cell purity was assessed by flow cytometric analysis. A total of 2$4 \times 10^{4}$ cells were incubated at $4^{\circ} \mathrm{C}$ for $30 \mathrm{~min}$ in $1 \%$ BSA with 10 


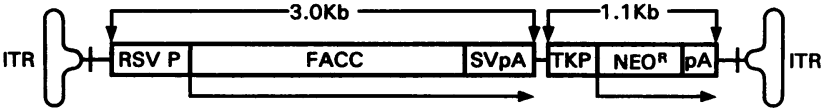

Figure 1. Construction of the $\mathrm{rAAV} / \mathrm{FACC} / \mathrm{Neo}^{\mathrm{R}}$ plasmid. The FACC cDNA coding sequence was inserted into an expression cassette and linked to the $\mathrm{Neo}^{\mathrm{R}}$ gene. These transcription units were then subcloned into psub201. The orientation and size $(\mathrm{kb})$ of each gene are indicated.

$\mu \mathrm{l}$ phycoerythrin-conjugated anti-CD34 antibody (mouse anti-human HPCA2; Becton Dickinson, Mountain View, CA). After they were washed, cells were analyzed on a Coulter Epics FACS. The percentage of cells staining for the CD34 antigen was compared with that of cells stained with an isotypic control (IgG 2a mouse anti-human antibody; Becton Dickinson)

rAAV CD34+ cell transduction and CFU-C assay. CD34+ immunoselected cells were cultured at a density of $6 \times 10^{4}$ or $6 \times 10^{5}$ per $\mathrm{ml}$ in IMDM, $15 \%$ fetal calf serum containing $20 \mathrm{ng} / \mathrm{ml}$ human interleukin-3 (IL-3, donated by Dr. Robert E. Donahue, Hematology Branch, NHLBI), $100 \mathrm{ng} / \mathrm{ml}$ human stem cell factor (SCF; Amgen Inc., Thousand Oaks, CA), and $50 \mathrm{ng} / \mathrm{ml}$ human interleukin 6 (IL-6, donated by Dr. Robert E. Donahue). rAAV lysate was added to maintain a multiplicity of infection of 0.1 . Cells were incubated overnight, spun down and resuspended in fresh media and viral lysate. This protocol was repeated for $3 \mathrm{~d}$. Mock-infected cells grown only in media and colony stimulating factors served as controls.

After infection, $1 \times 10^{5}$ cells were plated in $3.0 \mathrm{ml}$ methylcellulose (Terry Fox Labs, Vancouver, Canada) supplemented with SCF (100 $\mathrm{ng} / \mathrm{ml}), \mathrm{IL}-3$ (20 ng/ml), IL-6 (50 ng/ml), and recombinant human erythropoietin $(3 \mathrm{U} / \mathrm{ml})$. Of this $3.0 \mathrm{ml}$ mixture, $1.0 \mathrm{ml}$ was plated in colony culture petri dishes (Nunc). MMC was added directly to methylcellulose cultures to final concentrations of 1-10 nM. Cultures were grown in a humidified atmosphere at $37^{\circ} \mathrm{C}$ and $5 \% \mathrm{CO}_{2}$. Colonies were counted at day 15 .

Reverse transcriptase-polymerase chain reaction analysis of $\mathrm{CFU}$ $C$. Individual progenitor colonies containing 50-500 cells were harvested from methylcellulose into $50 \mu 1$ of RNA Stat-60 (Tel-Test B Inc., Friendswood, TX) containing $10 \mu \mathrm{g}$ transfer RNA and immediately frozen at $-70^{\circ} \mathrm{C}$. The RNA was isolated after chloroform extraction and precipitation with isopropanol. The sample was washed with ethanol, air dried, and resuspended in RNase-free water. An aliquot of each sample was reverse transcribed using the RNA PCR reagent kit (Perkin-Elmer Corp.) for $30 \mathrm{~min}$ at $42^{\circ} \mathrm{C}$. Identical reactions without reverse transcriptase were performed. $20 \mu \mathrm{l}$ of the cDNA generated was amplified using the manufacturer's recommended conditions and included $\mathrm{P}^{32} \mathrm{dCTP}$ ( $800 \mathrm{Ci} / \mathrm{mmol}$, Amersham Corp.). Primers mentioned previously were used for amplification. The conditions for amplification included: $95^{\circ} \mathrm{C}$ for $2 \mathrm{~min}$, followed by 35 cycles at $95^{\circ} \mathrm{C}$ for $1 \mathrm{~min}$, $60^{\circ} \mathrm{C}$ for $1 \mathrm{~min}$, and $72^{\circ} \mathrm{C}$ for $2 \mathrm{~min}$, followed by extension at $72^{\circ} \mathrm{C}$ for $8 \mathrm{~min}$. PCR-generated products were run on $5 \%$ polyacrylamide gels and autoradiographed.

\section{Results}

Phenotypic correction of FACC lymphoblasts by rAAV-mediated gene transfer. EBV-transformed lymphoblast cell lines derived from $\mathrm{FA}(\mathrm{C})$ patients were used to study in vitro gene complementation and functional correction of the FA defect. Two established cell lines from patients known to bear FACC mutant alleles were used to determine if a rAAV vector containing a copy of the normal FACC cDNA could correct the FA defect. The BD0215 lymphoblast cell line is homozygous for a nonsense mutation in exon 6 of the FACC coding sequence (25). The mutation causes a premature termination of translation at amino acid residue 185 , producing a truncated nonfunctional FACC protein. Lymphoblast cell line HSC536 contains

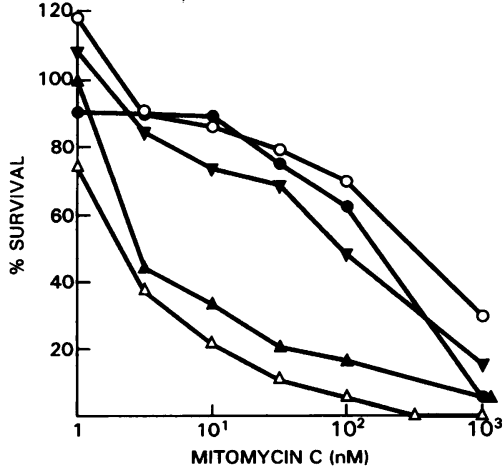

Figure 2. Analysis of rAAV/FACC-transduced lymphoblast mitomycin C sensitivity. Plot of cell viability of $\mathrm{FA}(\mathrm{C})$ lines BD0215 ( $\triangle$ ), HSC536 $(\triangle)$, normal lymphoblasts (O), rAAV/ FACC-transduced $\mathrm{BD0215}(\nabla)$, and rAAV/ FACC-transduced HSC536 (•) after incubation for $5 \mathrm{~d}$ with varying concentrations of MMC.

a $\mathrm{T}$ to $\mathrm{C}$ transition leading to an amino acid substitution of leucine to proline (designated L554P). This mutation completely abolishes the activity of the FACC protein in functional assays (26). Recombinant AAV virus, carrying the FACC cDNA in an expression cassette linked to the selectable gene $\mathrm{Neo}^{\mathrm{R}}$ (Fig. 1), was generated and used to infect FA(C) lymphoblast cell lines. G418-selected cells were used in functional complementation assays.

rAAV-mediated transfer and expression of the normal FACC gene corrected the defect in lymphoblast survival revealed by exposure to clastogenic agents such as MMC. Cells were incubated in the presence of varying concentrations of MMC for $5 \mathrm{~d}$, and viable cells were counted. Parental cells were highly sensitive to DNA cross-linking agents with an $\mathrm{EC}_{50}$ of 1.0-5.0 nM MMC. As shown in Fig. 2, cells transduced with rAAV were phenotypically altered so that the resistance of these lymphoblasts to MMC was comparable with that of normal lymphoblasts. The $\mathrm{EC}_{50}$ of transduced cells was 100 $500 \mathrm{nM}, 100$-fold higher than parental controls and comparable to the $\mathrm{EC}_{50}$ of normal cells.

Hypersensitivity of FA cells to DNA cross-linking agents is known to result in an increased frequency of chromosomal breakage. rAAV-transduced cells were analyzed for chromosomal breakage after incubation in MMC. As shown in Table I and Fig. 3, rAAV/HSC536 and rAAV/BD0215 cells had a significantly reduced number of chromosomal breaks and radials $(<5 \%)$ compared with mock-infected parental cells $\sim 50 \%$ of which had multiple chromosomal breaks and radial formation. The transduced cell lines no longer met the diagnostic criteria for FA, defined cytogenetically as $>20 \%$ radial formation. Notably, these rAAV-transduced cells were routinely passaged without selection more than 50 times before use in the

Table I. Chromosomal Breakage Analysis of $F A(C)$ Lymphoblasts

\begin{tabular}{lc}
\hline \multicolumn{1}{c}{ Cell line } & Radials*‡ $^{*}$ \\
& $\%$ \\
HSC536 & 48.0 \\
BD0215 & 36.0 \\
HSC536/rAAV/FACC/Neo & 6.0 \\
BD0215/rAAV/FACC/Neo & \\
\end{tabular}

* 50 cells from each cell line analyzed after a 2-day exposure to MMC $(40 \mathrm{ng} / \mathrm{ml}) . \quad{ }^{\ddagger}>20 \%$ of cells with radial formation are diagnostic for FA phenotype. 
A

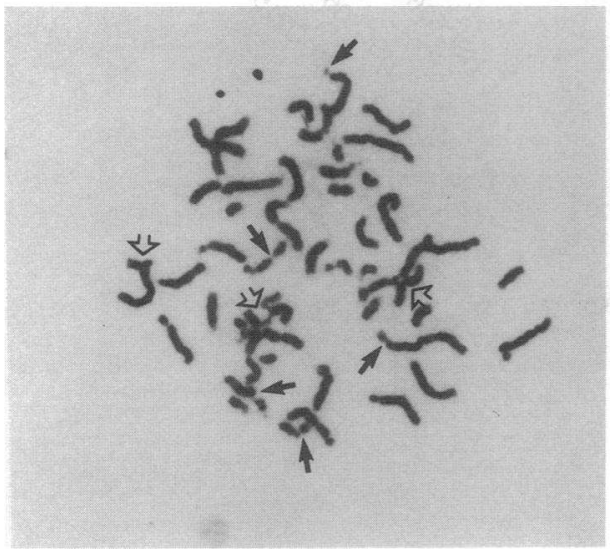

B

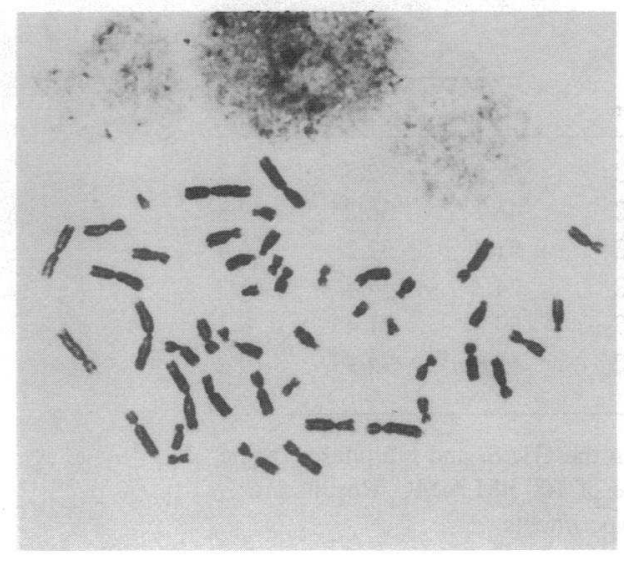

Figure 3. Cytogenetic analysis of rAAV-transduced lymphoblasts. (A) A representative metaphase spread from the cell line BD0215 after incubation with MMC (40 $\mathrm{ng} / \mathrm{ml}$ ). Chromatid breaks, gaps $(\bullet)$, and radials $(\Delta)$ are indicated. $(B)$ Metaphase preparation of rAAV/FACC-transduced BD0215 cells after exposure to MMC. cytogenetic assay. This implied that stable integration of the rAAV provirus had occurred.

FA cells in each phase of the cell cycle were analyzed by propidium iodide staining and flow cytometry (Fig. 4, Table II). The percentage of cells in the G2 phase is increased in FA patients as compared with normal individuals; this has been

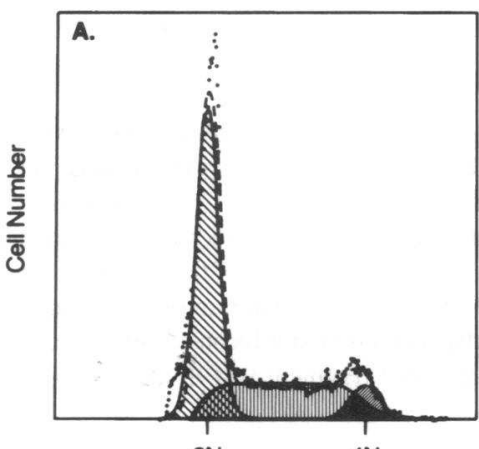

$2 \mathrm{~N}$

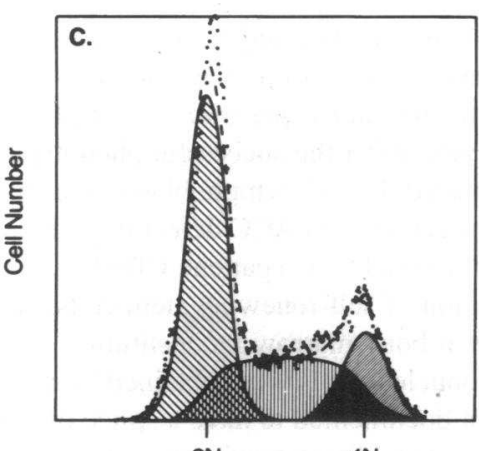

$2 \mathrm{~N}$

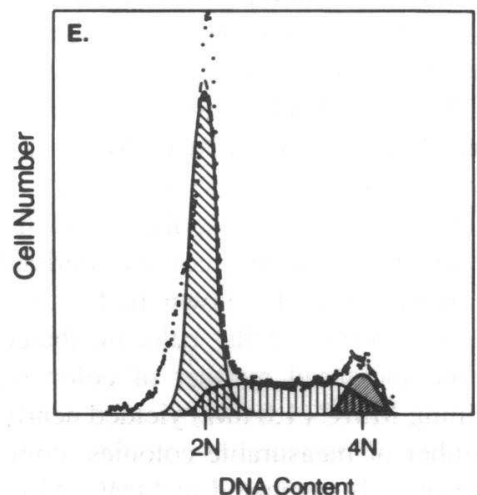

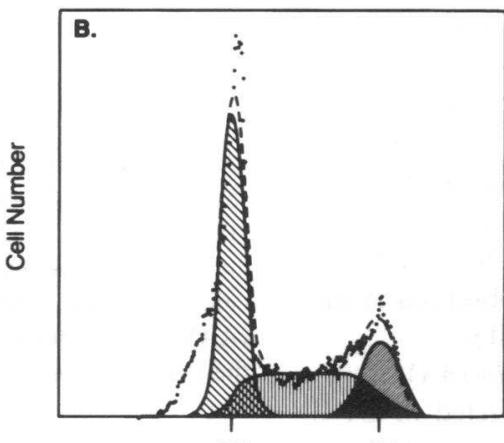

$2 \mathrm{~N}$

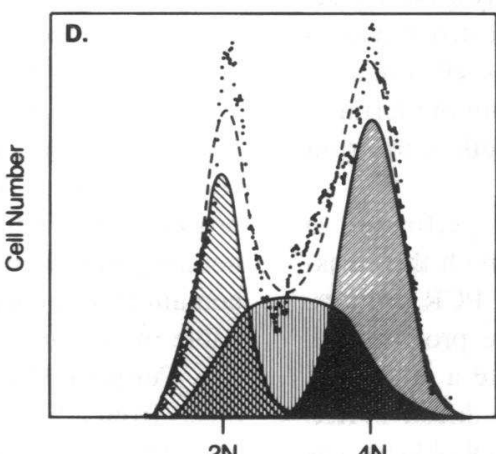

$2 \mathrm{~N} \quad 4 \mathrm{~N}$

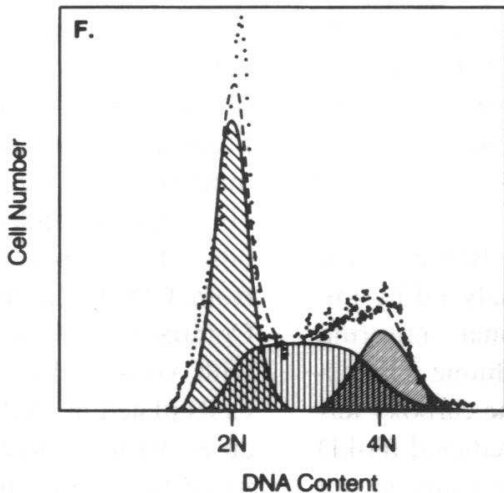

Figure 4. Effect of mitomycin C on DNA flow cytometry histograms of rAAV-transduced lymphoblasts. The rAAV-transduced FA lymphoblast cell line (BD0215) was compared to the parental and normal lymphoblast cell lines. Cells were harvested, stained with propidium iodide, and DNA histograms were obtained $24 \mathrm{~h}$ after cells were exposed to $100 \mathrm{nM}$ MMC $(B, D$, and $F) . A, C$, and $E$ are untreated cells. Lymphoblasts from a normal individual: $A$ and $B$; FA lymphoblasts (BD0215): $C$ and $D$; rAAV-transduced lymphoblasts: $E$ and $F$. Data is expressed as number of cells (ordinate) versus DNA content. Raw data are shown with data smoothed by MULTIPLIER. Areas under the curve for G1, S, and G2 are shown. 
Table II. Cell Cycle Analysis of rAAV Transduced Lymphoblasts

\begin{tabular}{lcccr}
\hline & & \multicolumn{3}{c}{ Cell number } \\
\cline { 3 - 5 } \multicolumn{1}{c}{ Cell type } & Condition & G1 & S & G2 \\
\cline { 3 - 5 } & & & & \\
\hline Normal lymphoblast & -MMC & 58.8 & 32.5 & 8.7 \\
Normal lymphoblast & +MMC & 46.1 & 36.8 & 17.8 \\
BD0215 lymphoblast & -MMC & 51.4 & 32.2 & 16.4 \\
BD0215 lymphoblast & +MMC & 24.3 & 34.4 & 41.3 \\
BD0215/rAAV & -MMC & 59.6 & 31.4 & 9.1 \\
BD0215/rAAV & +MMC & 45.9 & 34.9 & 19.2 \\
& & & & \\
\hline
\end{tabular}

* Refers to the percentage of cells in the G1, S, and G2 phases of the cell cycle in the absence or presence of $100 \mathrm{nM}$ MMC. Results are from duplicate samples from two experiments.

used diagnostically for evaluation of patients $(27,28)$. The major effect of MMC on DNA flow histograms was the expected increase in the number of cells in G2 (see Fig. 4). Cell cycle analysis of lymphoblasts derived from a normal individual in the absence and presence of MMC ( $100 \mathrm{nM})$ indicated only a modest increase (8\%) in the number of cells delayed in $\mathrm{G} 2$ phase (Fig. 4, $A$ and $B$, and Table II). A marked delay in G2 transit was observed when the parental lymphoblast cell line BD0215 was incubated with MMC (Fig. 4, $C$ and D). The percentage of cells in G2 increased from 16 to $41 \%$ (Table II). In marked contrast, cells from the rAAV-transduced FA line showed normalized cycle kinetics in both the absence or presence of MMC (Fig. 4, $E$ and $F$, and Table II). No significant change in the number of cells in $S$ phase was observed at the concentration of MMC tested (shown in Table II).

Structure and expression of the FACC gene in rAAV transduced lymphoblasts. rAAV-transduced cells selected in G418 were pooled and characterized by Southern blot analysis of genomic DNA. Shown in Fig. 5 are Southern analyses of DNAs from $\mathrm{rAAV} / \mathrm{FACC} / \mathrm{Neo}^{\mathrm{R}}$ transduced cells hybridized with a probe recognizing a fragment of the neomycin phosphotransferase gene. Digestion with SnaBI, which cuts within the termini, resulted in a single DNA band of predicted length, consistent with unrearranged integration of the provirus.

A reverse transcription (RT)-PCR assay was performed to determine the relative level of expression from both the transduced and endogenous FACC coding sequences. PCR primers, specific for the $3^{\prime}$ untranslated sequences of the proviral and native FACC mRNAs, were designed to generate a 602-bp or a 486-bp product from the endogenous or transduced FACC gene, respectively. Total RNA isolated from lymphoblasts was reverse transcribed and the CDNA used for the PCR amplification (Fig. 6). An mRNA signal for the endogenous FACC product was obtained from mock-infected HSC536 cells. As expected, no mRNA signal was observed using primers for the transduced FACC gene. However, both the endogenous and proviral mRNAs were amplified from lymphoblasts transduced with $\mathrm{rAAV} / \mathrm{FACC} / \mathrm{Neo}^{\mathrm{R}}$.

FACC protein expression in normal, parental BD0215, and transduced BD0215/rAAV lymphoblasts was analyzed by immunoprecipitation (Fig. 7). The rabbit polyclonal antiserum used was generated from an epitope of a glutathione S-transferase (GST)-FACC fusion protein directed to the carboxy terminus of FACC (amino acids 281-558). The predicted 63-kD FACC protein was detected in both normal and transduced cell

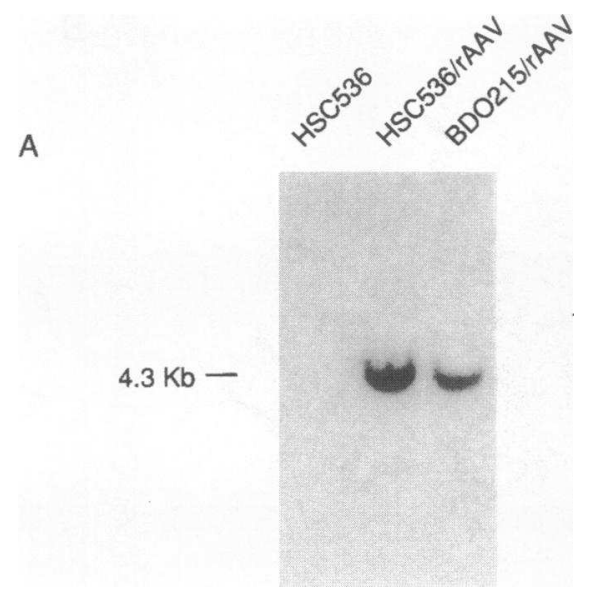

B

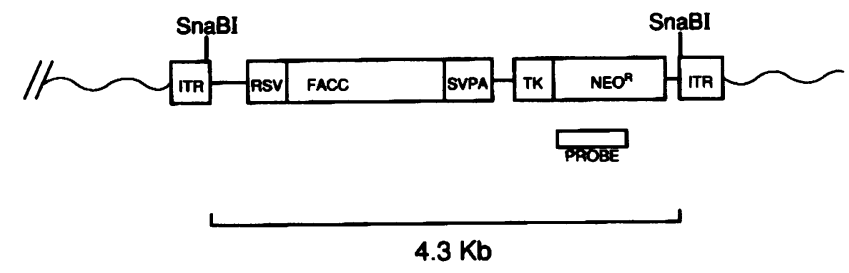

Figure 5. Southern blot analysis of FA(C) lymphoblasts infected with rAAV/FACC virus. ( $A$ ) SnaBI digestion of genomic DNA isolated from rAAV/FACC-transduced BD0215, rAAV/FACC-transduced HSC536, and HSC536 cell lines. The expected 4.3-kb band represents an intact, unrearranged rAAV proviral form. HSC536 mock-infected cells served as a control DNA. $(B)$ Schematic diagram of the integrated rAAV proviral form. The SnaBI restriction site located within each of the ITRs is indicated. A $197-\mathrm{bp} \mathrm{Neo}{ }^{\mathrm{R}}$ fragment was used as probe.

lines. As expected, no protein was detected from the parental line with a predicted truncated protein of 185 amino acids.

$A A V$-mediated gene transfer and expression into CD34+ hematopoietic progenitor cells. After the successful phenotypic correction of rAAV-transduced FACC lymphoblasts, we approached the problem of correcting the FACC defect in primary hematopoietic cells derived from a FA(C) patient. CD34+ cells contain an enriched population of self-renewing stem cells, capable of sustaining long-term bone marrow reconstitution (29, 30). Peripheral blood mononuclear cells were obtained by apheresis from a FA(C) patient documented to have a splice mutation at FACC intron 4 ( $A$ to $\mathrm{T}$ ) yielding a nonfunctional protein. Selected cells were isolated using a column containing an avidin-coated matrix that absorbs the human CD34-biotin-conjugated antibody. Flow cytometric analysis of the isolated cells revealed that $92 \%$ of the cells were CD34+ after immunopurification. Cells were incubated with $\mathrm{rAAV} / \mathrm{FACC} / \mathrm{Neo}^{\mathrm{R}}$ at a multiplicity of infection (moi) of 0.1 for $3 \mathrm{~d}$, washed, and $3 \times$ $10^{4}$ cells suspended in methylcellulose, as described in Methods. After a 15-d culture period, hematopoietic colonies derived from CD34-enriched cells were counted (shown in Fig. 8). Compared with mock-infected CD34+ cells, cells incubated with virus yielded a fourfold increased number of colonies. Cells plated in media containing MMC $(1.0 \mathrm{nM})$ yielded nearly an 8-10-fold increased number of measurable colonies, compared to nontransduced control cells incubated in MMC. Mor- 


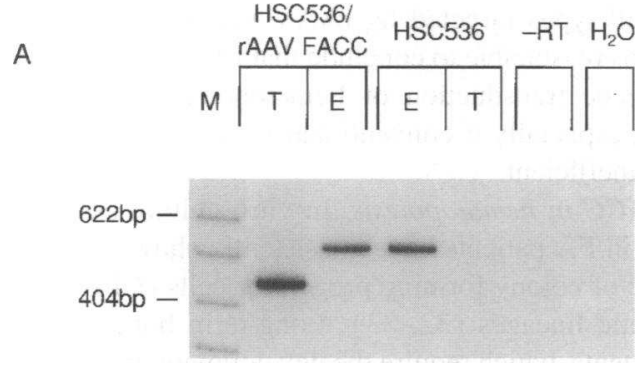

B

\section{RT-PCR ASSAY}

FACC
$\begin{gathered}\text { ENDOGENOUS } \\ \text { SPECIFIC } \\ \text { PRIMERS (E) }\end{gathered}$

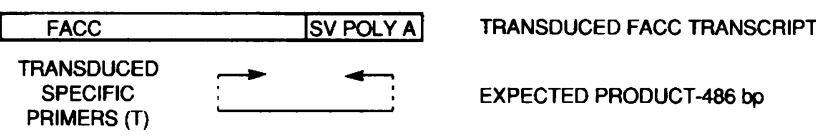

Figure 6. Expression of FACC mRNA in FA(C) lymphoblasts measured by the polymerase chain reaction. $(A)$ Total RNAs isolated from rAAV-infected HSC536 and mock-infected HSC536 were analyzed for both endogenous and transduced FACC transcription. Primers specific for the endogenous FACC transcript (E) and the transduced FACC transcript ( $T$ ) are indicated. RNA processed identically without reverse transcriptase (RT) and samples without RNA (labeled $\mathrm{H}_{2} \mathrm{O}$ ) served as negative controls. $(B)$ The expected 602 - or 486 -bp products generated using reverse-transcribed RNA from the endogenous FACC gene and the transduced FACC gene, respectively.

phologically, the majority of colonies were of the myeloid/ macrophage lineage (CFU-GM).

RT-PCR analysis was used to verify that the MMC progenitor colonies were transduced by rAAV. Apparent MMC-resistant colonies were isolated; total RNA was obtained and analyzed by RT-PCR using conditions described in Methods. The autoradiograph in Fig. 9 demonstrated the appropriate 486-bp size fragment in 6 of 9 colonies assayed. RNA not reverse transcribed generated no signal and ruled out the possibility of DNA contamination. Analysis of additional colonies demonstrated that $60 \%$ of colonies yielded the expected 486-bp signal without detectable contaminating DNA (data not shown). Although the majority of colonies scored positive for rAAC/ FACC expression, some colonies did not express FACC as determined by our RT-PCR assay. RT-PCR results using $\beta$ actin primers generated the appropriate signal in all of the FA(C) colonies analyzed (data not shown).

\section{Discussion}

We have shown that a recombinant AAV vector can transfer a functioning copy of the normal FACC gene to FA(C) lymphoblasts and CD34+ hematopoietic progenitors, correcting the phenotypic defect of these cells. Phenotypic correction was determined by resistance of cells to MMC-induced cell death and insusceptibility to chromosomal breakage in lymphoblastoid cell lines. Corrected cell lines represented two distinct
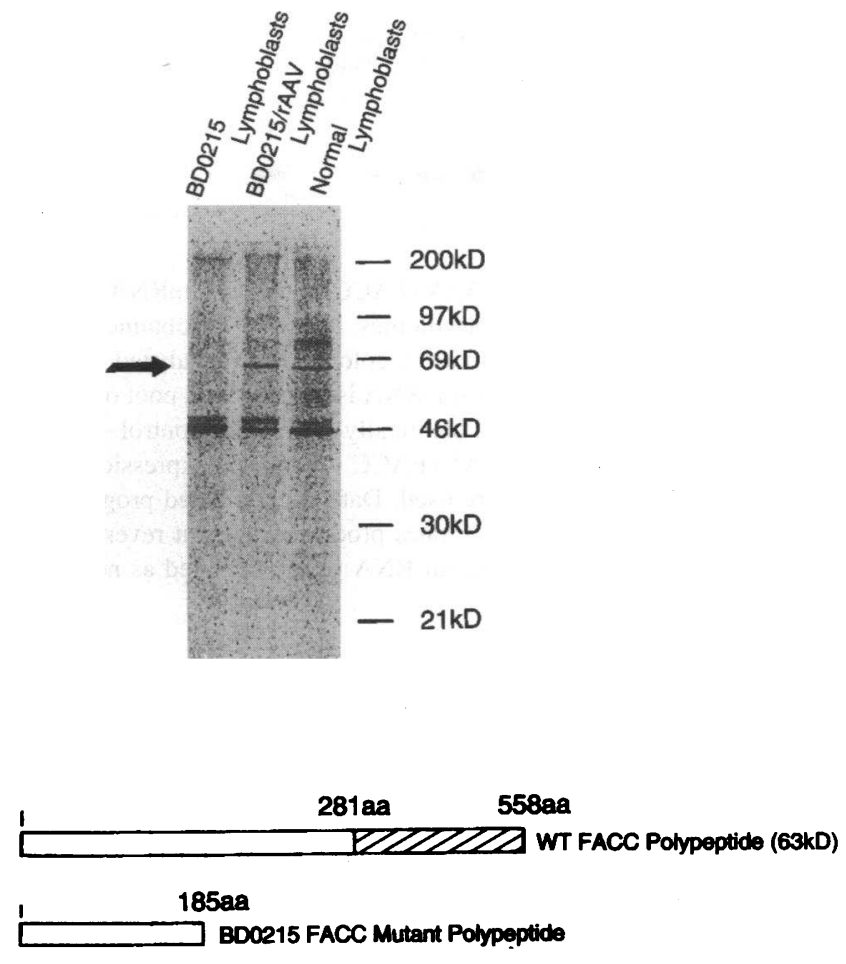

Figure 7. Immunoprecipitation analysis of normal, mutant (BD0215), and rAAV/transduced BD0215 lymphoblasts. Cells were labelled with $\left[{ }^{35} \mathrm{~S}\right]$ methionine and radiolabeled proteins immunoprecipitated with anti-FACC antiserum. Proteins were resolved on a 10\% SDS/polyacrylamide gel. Arrow indicates the predicted molecular weight of the wildtype FACC polypeptide. The expected sizes of the wild-type and mutant FACC proteins are shown schematically below. A GST-FACC fusion protein containing FACC amino acid sequence $281-558$, indicated by the hatched region, was used to generate rabbit antiserum. Molecular weight markers are indicated at the right.

FACC mutations known to result in the disease phenotype. Using PCR analysis, the level of rAAV/FACC expression appeared to be equivalent to that of the endogenous gene. Transduced lymphoblasts maintained a corrected phenotype over more than 50 cell passages without selection, consistent with stable proviral integration. Of importance to the application of

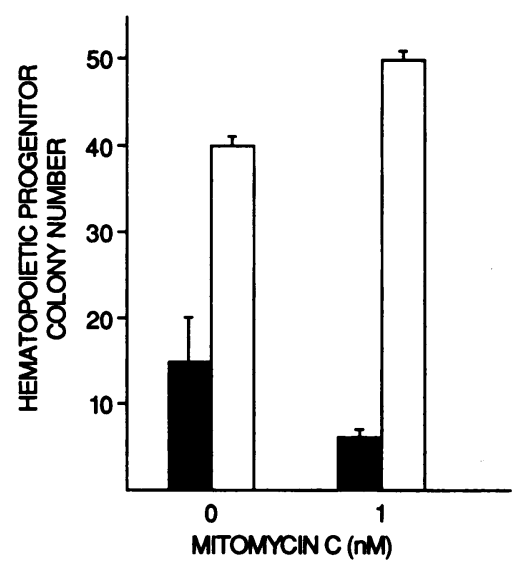

Figure 8. Analysis of hematopoietic progenitor colony growth following rAAV/FACC infection of $\mathrm{CD} 34+$ cells isolated from a $F A(C)$ patient.

The number of progenitor colonies ( $>50$ cells/ colony) measured at day 15 in methylcellulose culture following rAAV/ FACC virus ( $\square$ ) or mock infection (匹) are shown. Cells were grown in either the absence or presence of $1 \mathrm{nM}$ MMC. Results are expressed as mean colony number \pm SEM. 


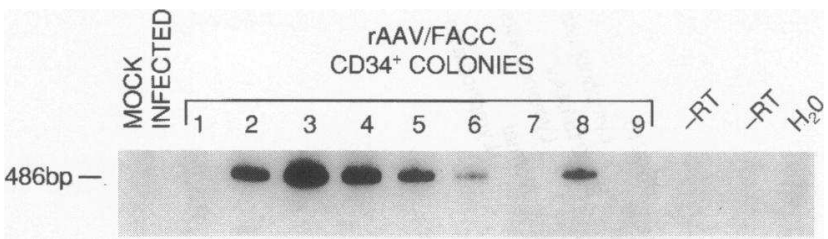

Figure 9. RT-PCR analysis of rAAV/FACC-transduced mRNA expression in hematopoietic progenitor colonies. Total RNAs obtained from apparent MMC-resistant bone marrow colonies were analyzed for rAAV/FACC-specific transcription. RNA isolated from a pool of mockinfected colonies was processed identically to serve as control. Primers specific for the detection of rAAV/FACC transduced expression, the predicted 486-bp fragment, were used. Data from isolated progenitor colonies are shown. RNA from clones processed without reverse transcriptase (RT) and samples without RNA were employed as negative controls.

rAAV vectors to the gene therapy of Fanconi anemia, we also demonstrated rAAV transduction of primary hematopoietic cells by both functional and molecular studies. CD34+ immunoselected hematopoietic progenitors from an $\mathrm{FA}(\mathrm{C})$ patient transduced with rAAV demonstrated increased colony formation both in the absence and presence of MMC. Furthermore, RT-PCR analysis confirmed rAAV/FACC expression.

Recombinant $A A V$ gene transfer to hematopoietic cells. Testing the utility of the recombinant AAV vector system for gene transfer in hematopoietic progenitor cells was one of the main objectives of this study. The first report of transduction of murine hematopoietic progenitors described the use of a rAAV vector bearing a neo ${ }^{\mathrm{R}}$ gene with a transduction efficiency of only $1.5 \%$ (31). Transduction was determined solely from the number of geneticin-resistant bone marrow colonies. These early generation rAAV preparations were contaminated with wild type AAV virions which decreased rAAV transduction efficiency (13).

We have focused on the use of packaging systems which generate rAAV stocks devoid of wild type virions (23). We have used these helper-free rAAV vectors to transfer the $\beta$ galactosidase gene into primate $\mathrm{CD} 34+$ hematopoietic progenitor cells (22a). Enzyme expression was documented in 60 $70 \%$ of the infected cells. A more recent report claimed $80 \%$ transduction of unpurified murine progenitors when scored by neomycin-selected bone marrow progenitor assays (22). DNA PCR data from individual bone marrow colonies grown in G418 demonstrated rAAV infection and presumed proviral integration. However, work in our laboratory has suggested that DNA PCR analysis of bone marrow colonies must be interpreted cautiously. Both unintegrated virus and vector plasmid forms which may be associated with cells will be detected by PCR (J. L. Miller, unpublished results). For this reason, we used RT-PCR as a method to determine rAAV-transduced FACC expression in both human lymphoblasts and CD34+ primary hematopoietic progenitors.

It should be noted that $>90 \%$ of the FA(C) immunoaffinity-purified cells were CD34 antigen positive, suggesting that primitive populations of hematopoietic cells can be transduced with rAAV. Unfortunately, the efficiency of rAAV transduction is difficult to accurately assess, particularly when the moi is quite low. We presume that colonies arose from transduced pluripotential cells but we have no way to ascertain what fraction of the CD34+ population contain these cells. While the spectrum of cell types targeted by rAAV vectors needs to be defined, it seems reasonable to conclude that rAAV vectors may be useful in gene transduction of hematopoietic progenitors and stem cells, especially if conventional vector systems prove inadequate or inefficient.

Role of FACC in hematopoiesis. In vitro culture assays of hematopoiesis in FA patients have consistently shown a reduction or absence of colony forming progenitor cells (CFU-C) of all hematopoietic lineages $(32,33)$. Long-term bone marrow culture experiments, which require the development of an adherent stromal cell layer for the maintenance of progenitor growth, have also revealed a significant reduction in the number of CFU-C (34). Although defects of the bone marrow stromal elements cannot be totally excluded, fibroblasts (a major cell constituent of the stroma) from FA patients seem to express the appropriate repertoire of hematopoietic growth factors (35). Available evidence suggests, therefore, that FA is a disorder of a primitive hematopoietic stem cell. We have been able to show that $\mathrm{CD} 34+$ progenitors from a $\mathrm{FA}(\mathrm{C})$ patient retain the hypersensitivity to MMC which characterizes cultured FA cells.

In this study, we utilized the unique characteristics of the FACC gene to serve as a biological marker for rAAV/FACC gene transfer. As we demonstrated with rAAV-transduced FA(C) lymphoblasts, expression of the FACC gene in FACCdeficient cells promotes cell growth in the presence of MMC. The self-selecting growth advantage conferred by expression of the FACC gene was also evident from the results obtained following the incubation of virally transduced FA(C) progenitor cells with low dose MMC ( $1 \mathrm{nM})$, a dose which has no effect on colony growth of CD34 + cells from normal individuals. The increased colony growth reflects genetic rescue of CD34+ progenitor cells after rAAV/FACC transduction. FACC gene expression detected from the majority of progenitor cell colonies provides presumptive evidence that the growth advantage was due to expression of the normal gene in cells bearing defective FACC alleles. Notably, even in the absence of MMC, rAAV transduced CD34+ cells yielded a fourfold greater number of viable progenitor colonies compared with mock-infected controls. Conversely, normal hematopoiesis is inhibited when the FACC gene is repressed using antisense oligonucleotides incubated with normal bone marrow cells (36). We suggest that the FACC gene may therefore be involved in the maintenance of hematopoietic cell growth in addition to its role in the cellular response to DNA damage induced by agents such as MMC.

FACC biological function. The exact biochemical function of the FACC gene is not known, but recent data indicate that the gene product is expressed ubiquitously and conserved phylogenetically (37). Conflicting data exist concerning the subcellular location of the FACC protein $(38,39)$. Current hypotheses suggest that the FA defect involves DNA repair. Circumstantial evidence for aberrant repair processes is based upon the marked cellular hypersensitivity to bifunctional DNA cross-linking agents coupled with spontaneous and chemical-induced chromosomal instability. In our experiments, FACC gene-transduced lymphoblasts (as compared with parental controls) exhibited a markedly reduced susceptibility to chromosomal breakage after treatment with MMC. Radial formation is thought to result from chromatid exchange and was used diagnostically to score for aberrations in our experiments. Thus, FACC may be implicated in a primary or secondary pathway involved in the repair of DNA. One implication of our work is that the FACC gene may function at an early stage in the re- 
sponse of the cell to DNA damage, since complementation alters both chromosomal stability and (subsequently) cell survival.

FA cells are markedly retarded during progression through the $\mathrm{G} 2$ phase of the cell cycle $(7,40)$. rAAV-transduced FA lymphoblasts were phenotypically corrected not only in terms of MMC-induced cell survival and chromosomal aberrations but also demonstrated normalized cell cycle kinetics. At least two periods in the cell cycle are regulated in response to DNA damage, the G1-S and G2-M transitions. These "checkpoints" function as surveillance mechanisms which delay cell cycle progression and allow for the repair of damaged DNA. Both G1 and G2 checkpoints are known to be under genetic control (41). Many eukaryotic cells delay in the G2 phase of the cell cycle after DNA damage induced by a variety of chemical agents, $\gamma$-irradiation, or by inactivation of DNA replication or repair enzymes. The delay in the $\mathrm{G} 2$ phase provides the cell with additional time to complete DNA repair before mitosis; prevention of $\mathrm{G} 2$ arrest by chemical treatment (caffeine) or genetic mutation (Rad 9 mutants in $S$. cerevisiae) results in increased cytogenetic damage and cell death $(42,43)$. Caffeine treatment of FA cells shortens the duration of $G 2$ phase but does not lead to rapid death of cells exposed to MMC (44, 45); chromosomal breakage is dramatically increased (46), due possibly to loss of the $\mathrm{G} 2$ checkpoint. In contrast, we have shown that rAAV/FACC-transduced FA(C) cells exhibit normal cell cycle kinetics and normal cytogenetics when treated with MMC. By implication, the FACC gene product may function as a DNA repair enzyme, a surveillance protein, or as a factor coupling the two activities.

In summary, our experiments may shed light on the nature of the specific FA cellular defect as well as suggest new strategies for the treatment of patients. FA cells suffer from an increased generation time and from an increased rate of cell death. We have shown that the FACC gene product can alter (and normalize) both of these phenotypes in mutant cell lines and hematopoietic progenitor cells derived from a $\mathrm{FA}(\mathrm{C})$ patient. One interpretation of these data is that relief of $\mathrm{G} 2$ phase checkpoint arrest may enable improved cell survival. However, those cells not only survive MMC treatment but also exhibit fewer cytogenetic abnormalities. Thus, we infer that the FACC gene is able to correct some aspect of DNA damage which accumulates prior to the $\mathrm{G} 2$ phase. From the standpoint of therapeutic strategies for FA(C) patients, we believe that transfer of the FACC gene into appropriate hematopoietic target cells could allow for hematopoietic reconstitution with a genetically normalized pool of stem cells. Our data indicate that $\mathrm{rAAV}$ vectors can transduce primitive hematopoietic progenitor cells and correct an inherited defect and suggests that in vivo studies of rAAV gene therapy are warranted.

\section{Acknowledgments}

We thank Stacie Anderson for excellent technical assistance, Dr. M. Buchwald for the plasmid pFAC3 and cell line HSC536, Dr. C. Mathew for the cell line BD0215, Dr. M. Grompe, Dr. E. Magenis, and the Fanconi Anemia Research Fund. We also thank Drs. A. D'Andrea and T. Yamashita for providing the rabbit anti-FACC antiserum.

\section{References}

1. Alter, B., and N. S. Young. 1993. The bone marrow failure syndromes. In Hematology of Infancy and Childhood. D. G. Nathan, and F. A. Oski, editors W. B. Saunders, Philadelphia, PA. 216-316.

2. Gluckman, E., A. Devergie, and J. Dutreix. 1989. Bone marrow transplanta- tion for Fanconi anemia. In Fanconi Anemia. T. M. Schroeder-Kurth, A. D. Auerbach, and G. Obe, editors. Springer-Verlag, New York. 60-70.

3. Schroeder, T. M., F. Anschutz, and A. Knopp. 1964. Spontane Chromosomenaberrationen bei familiarer Panmyelopathie. Humangenetik. 1:194-196.

4. German, J., and C. L. Pugliatta. 1966. Chromosomal breakage in diploid cell lines from Bloom's syndrome and Fanconi's anemia. Ann. Genet. 9:143154.

5. Sasaki, M. S., and A. Tonomura. 1973. A high susceptibility of Fanconi's anemia to chromosome breakage by DNA cross-linking agents. Cancer Res. 33:1829-1836.

6. Auerbach, A. D., A. Rogatko, and T. M. Schroeder-Kurth. 1989. International Fanconi Anemia Registry: relation of clinical symptoms to diepoxybutane sensitivity. Blood. 73:391-396.

7. Kubbies, M., D. Schindler, H. Hoehn, and P. S. Rabinovitch. 1985. Endogenous blockage and delay of the chromosome cycle despite normal recruitment and growth phase explain poor proliferation and frequent edomitosis in Fanconi anemia cells. Am. J. Hum. Genet. 37:1022-1030.

8. Ishida, R., and M. Buchwald. 1982. Susceptibility of Fanconi's anemia lymphoblasts to DNA cross-linking and alkylating agents. Cancer Res. 42:40004006.

9. Strathdee, C. A., A. M. V. Duncan, and M. Buchwald. 1992. Evidence for at least four Fanconi anaemia genes including FACC on chromosome 9. Nature Genetics. 1:196-198.

10. Strathdee, C. A., H. Gavish, W. R. Shannon, M. Buchwald. 1992. Cloning of cDNAs for Fanconi's anaemia by functional complementation. Nature (Lond.). 356:763-776.

11. Verlander, P. C., J. D. Lin, M. U. Udono, R. A. Gibson, C. G. Mathew, S. L. Sherman, and A. D. Auerbach. 1993. Mutation and linkage analysis of the Fanconi anemia gene FACC. Hum. Genet. 53(suppl.):11a.

12. Whitney, M. A., H. Saito, P. M. Jakobs, R. A. Gibson, R. E. Moses, and M. Grompe. 1993. A common mutation in the FACC gene causes Fanconi anaemia in Ashkenazi jews. Nature Genetics. 4:202-205.

13. Muzyczka, N. 1992. Use of adeno-associated virus as a general transduction vector for mammalian cells. Curr. Top. Microbiol. Immunol. 158:97-129.

14. Nienhuis, A. W., C. E. Walsh, and J. Liu. 1993. Viruses as therapeutic gene transfer vectors. In Viruses and Bone Marrow Young. N. S. Young, editor Marcel Dekker, New York. 353-414.

15. Walsh, C. E., J. M. Liu, J. L. Miller, A. W. Nienhuis, and R. J. Samulski. 1993. Gene therapy for human hemoglobinopathies. Proc. Soc. Exp. Biol. Med. 204:289-300.

16. Kotin, R. M., R. Siniscalco, R. J. Samulski, X. Zhu, L. Hunter, C. A. Laughlin, S. McLaughlin, N. Muzyczka, M. Rocchi, and K. Berns. 1990. Sitespecific integration by adeno-associated virus. Proc. Natl. Acad. Sci. USA. 87:2211-2215.

17. Samulski, R. J., X. Zhu, X. Xiao, J. D. Brook, D. E. Housman, N. Epstein, and L. A. Hunter. 1991. Targeted integration of adeno-associated virus (AAV) into human chromosome 19. EMBO (Eur. Mol. Biol. Organ.) J. 10:3941-3950.

18. Samulski, R. J. 1993. Adeno-associated virus: integration at a specific chromosomal locus. Current Opinion in Genetics and Development. 3:74-80.

19. Walsh, C. E., J. M. Liu, X. Xiao, N. S. Young, A. W. Nienhuis, and R. J. Samulski. 1992. Regulated high level expression of a human $\gamma$-globin gene introduced into erythroid cells by an adeno-associated virus vector. Proc. natl. Acad. Sci. USA. 89:7257-7261.

20. Miller, J. L., C. E. Walsh, P. A. Ney, R. J. Samulski, and A. W. Nienhuis 1993. Single-copy transduction and expression of the human $\gamma$-globin in K562 erythroleukemia cells using recombinant adeno-associated virus vectors: the effect of mutations in NF-E2 and GATA-1 binding motifs within the hypersensitivity site 2 enhancer. Blood. 82:1900-1906.

21. Chatterjee, S., P. R. Johnson, and K. K. Wong. 1992. Dual target inhibition of HIV-1 in vitro by means of an adeno-associated virus antisense vector. Science (Wash. DC). 258:1485-1488.

22. Zhou, S. Z., H. E. Broxmeyer, S. Cooper, M. A. Harrington, and A Srivastava. 1993. Adeno-associated virus 2-mediated gene transfer in murine hematopoietic progenitor cells. Exp. Hematol. (NY). 21:928-933.

22a. Goodman, S., X. Xiao, R. E. Donahue, A. Moulton, J. Miller, C. Walsh, N. S. Young, R. J. Samulski, and A. W. Nienhuis. 1994. Recombinant adenoassociated virus-mediated gene transfer into hematopoietic progenitor cells. Blood. In press.

23. Samulski, R. J., L. S. Chang, and T. Shenk. 1989. Helper-free stocks of recombinant adeno-associated viruses: normal integration does not require vira gene expression. J. Virol. 63:3822-3828.

24. Rigaud, G., T. Grange, and R. Picet. 1987. The use of $\mathrm{NaOH}$ as transfer solution of DNA onto nylon membranes decreases the hybridization efficiency. Nucleic Acids Res. 15:857.

25. Gibson, R. A., A. Hajianpour, M. Murer-Orlando, M. Buchwald, and C. G. Mathew. 1993. A nonsense mutation and exon skipping in the Fancon anemia group C gene. Hum. Mol. Gen. 2:797-799.

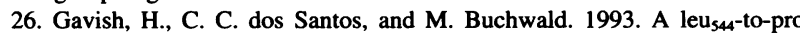
substitution completely abolishes the functional complementing activity of the Fanconi anemia (FACC) protein. Hum. Mol. Gen. 2:123-126.

27. Kaiser, T. N., A. Lojewski, C. Dougherty, L. Juergens, E. Sahar, and S. A 
Latt. 1982. Flow cytometry characterization of the response of Fanconi's anemia cells to mitomycin C treatment. Cytometry. 2:291-297.

28. Berger, R., M. LeConieat, and M-C Gendron. 1993. Fanconi anemia chromosome breakage and cell cycle studies. Cancer Genet. Cytogenet. 69:1316.

29. Andrews, R G., J. W. Singer, and I. D. Bernstein. 1990. Human hematopoietic precursors in long term culture: single CD34+ cells that lack detectable $\mathrm{T}$ cell, $\mathrm{B}$ cell, and myeloid cell antigen produce multiple colony-forming cells when cultured with marrow stroma. J. Exp. Med. 172:355-358.

30. Verfaillie, C., K. Blakolmer, and P. McGlave. 1990. Purified primitive human hematopoietic progenitor cells with long-term in vitro repopulating capacity adhere selectively to irradiated bone marrow stroma. J. Exp. Med. 172:509520.

31. LaFace, D., P. Hermonat, and A. Peck. 1988. Gene transfer into hematopoietic progenitor cells mediated by an adeno-associated virus vector. Virology. 162:483-486.

32. Saunders, E. F., and M. H. Freedman. 1978. Constitutional aplastic anaemia: defective haematopoietic stem cell growth in vitro. Br. J. Haematol. 40:277287.

33. Alter, B. P., M. E. Knobloch, L. He, A. P. Gillio, R. J. O'Reilly, L. K Reilly, and R. S. Weinberg. 1992. Effect of stem cell factor on in vitro erythropoiesis in patients with bone marrow failure syndromes. Blood. 80:3000-3008.

34. Stark, R., D. Theirry, P. Richard, and E. Gluckman. 1993. Long-term bone marrow culture in Fanconi's anaemia. Br. J. Haematol. 83:554-559.

35. Bagby, G. C., G. M. Segal, A. D. Auerbach, T. Onega, W. Keeble, and M. C. Heinrich. 1993. Constitutive and induced expression of hematopoietic growth factor genes by fibroblasts from children with Fanconi anemia. Exp. Hematol. (NY). 21:1419-1426.
36. Segal, G. M., E. Magenis, M. Brown, T. D. Smith, W. Keeble, and G. C. Bagby. 1993. Repression of the Fanconi anemia complementation group $\mathrm{C}$ gene (FACC) inhibits normal hematopoiesis in vitro. Clin. Res. 41:276A.

37. Wevrick, R., C. A. Clarke, M. Buchwald. 1993. Cloning and analysis of the murine Fanconi anemia group C cDNA. Hum. Mol. Gen. 2:655-662.

38. Gavish, H., C. A. Clarke, W. R. Shannon, M. Buchwald. 1993. The Fanconi anemia (FACC) protein is primarily localized in the nucleus. Hum. Genet. 53(suppl):685a.

39. Youssoufian, H. 1993. Subcellular localization of Fanconi's anemia C protein by epitope-tagging. Hum. Genet. 53(suppl)656a.

40. Dutrillaux B., A. Aurias, A. M. Dutrillaux, D. Buriot, and M. Prieur. 1982. The cell cycle of lymphocytes in Fanconi anemia. Hum. Genet. 62:327-332.

41. Hartwell, L. H., and T. A. Weinert. 1989. Checkpoints: controls that ensure the order of cell cycle events. Science (Wash. DC). 246:629-634.

42. Lau, C. C., and A. B. Pardee. 1982. Mechanism by which caffeine potentiates lethality of nitrogen mustard. Proc. Natl. Acad. Sci. USA. 79:2942-2946.

43. Weinert, T. A., and L. H. Hartwell. 1988. The rad9 gene controls the cell cycle response to DNA damage in saccharomyces cerevisiae. Science (Wash. DC). 241:317-322.

44. Sabatier, L., and B. Dutrillaux. 1988. Effect of caffeine in Fanconi anemia I. Restoration of a normal duration of G2 phase. Hum. Genet. 79:242-244.

45. Frazelle, J. H., J. S. Harris, and M. Swift. 1981. Response of Fanconi anemia fibroblasts to adenine and purine analogues. Mutat. Res. 80:373-380.

46. Pincheira, J., M. Bravo, and J. F. Lopez-Saez. 1988. Fanconi's anemia lymphocytes: effect of caffeine, adenosine and niacinamide during G2 prophase. Mutat. Res. 199:159-165. 